Original Paper

\title{
Association between subjective evaluation and physical parameters for radiographic images optimization
}

\author{
A.F.F. Alves ${ }^{\text {a }}$, M. Alvarez ${ }^{\text {a }}$, S.M. Ribeiro ${ }^{\text {b }}$, S.B. Duarte ${ }^{\text {c }}$, J.R.A. Miranda ${ }^{a}$, D.R. Pina ${ }^{\text {b,* }}$ \\ a Department of Physics and Biophysics, Biosciences Institute of Botucatu, São Paulo State University, Distrito de Rubião Junior S/N, Botucatu, São Paulo, \\ 18618-000, Brazil \\ ${ }^{\mathrm{b}}$ Department of Tropical Diseases and Diagnostic Imaging, Botucatu Medical School São Paulo State University, Distrito de Rubião Junior S/N, Botucatu, São \\ Paulo, 18618-000, Brazil \\ ${ }^{\mathrm{c}}$ Brazilian Center of Physics Research - CBPF-MCT, Dr. Xavier Sigaud, 150, Rio de Janeiro, 22290-180, Brazil
}

\section{A R T I C L E I N F O}

\section{Article history:}

Received 22 July 2015

Received in revised form 28 October 2015

Accepted 30 October 2015

Available online 10 November 2015

\section{Keywords:}

Radiology

Computed radiography

Image quality

Dose

\begin{abstract}
A B S T R A C T
Purpose: The purpose of this study was to develop a methodology to optimize computed radiographic techniques to image the skull, chest, and pelvis of a standard patient.

Methods: Optimization was performed by varying exposure levels with different tube voltages to generate images of an anthropomorphic phantom. Image quality was evaluated using visual grading analysis and measuring objective parameters such as the effective detective quantum efficiency and the contrastto-noise ratio. Objective and subjective evaluations were compared to obtain an optimized technique for each anatomic region.

Results: Gold standard techniques provided a significant reduction in X-ray doses compared to the techniques used in our radiology service, without compromising diagnostic accuracy. They were chosen as follows $102 \mathrm{kVp} / 1.6 \mathrm{mAs}$ for skull; $81 \mathrm{kVp} / 4.5 \mathrm{mAs}$ for pelvis and $90 \mathrm{kVp} / 3.2 \mathrm{mAs}$ for chest.

Conclusion: There is a range of acceptable techniques that produce adequate images for diagnosis in computed radiography systems. This aspect allows the optimization process to be focused on the patient dose without compromising diagnostic capabilities. This process should be performed through association of quantitative and qualitative parameters, such as effective detective quantum efficiency, contrast-tonoise ratio, and visual grading analysis.
\end{abstract}

(C) 2015 Associazione Italiana di Fisica Medica. Published by Elsevier Ltd. All rights reserved.

\section{Introduction}

Optimization of radiographic techniques aims to balance image quality and exposure dose to the patient and is outlined in the As Low As Reasonably Achievable (ALARA) principle [1-3]. Dose levels are related to image quality, but it should not be minimized to a degree that compromises diagnostic capabilities [1,2,4-6].

Image quality can be estimated subjectively using a Visual Grading Analysis (VGA), which is a direct analysis of the image by radiologists and can be performed in anthropomorphic phantom radiographs [7]. However, particularly with digital systems, sometimes VGA is not sufficient to make distinctions between different techniques.

In this case, objective parameters are extremely useful to investigate image quality and numerous attempts were made to optimize

\footnotetext{
* Corresponding author. Prof. Montenegro Avenue, Rubião Junior District, Botucatu, São Paulo, 18618-970, Brazil. Tel.: +55 14 38801281; fax: +55 1438801674.

E-mail addresses: allan@ibb.unesp.br (A.F.F. Alves), matheus@ibb.unesp.br (M. Alvarez), sribeiro@fmb.unesp.br (S.M. Ribeiro), sbd@cbpf.br (S.B. Duarte),jmiranda@ ibb.unesp.br (J.R.A. Miranda), drpina@fmb.unesp.br (D.R. Pina).
}

digital radiography systems. For example, some authors investigated the association of signal-to-noise ratio (SNR) and clinical observer evaluations to optimize images [8]. Additionally contrastto-noise ratio (CNR) was used to optimize beam quality for regions of different attenuation such as the lung, heart, and abdomen [9].

Other metrics such as the detective quantum efficiency (DQE) and the effective DQE (eDQE) have been used to assess image quality in digital radiography systems $[10,11]$. The eDQE seems adequate to characterize system performance in a relevant clinical context, although it lacks the incorporation of the risk to the patient, which is evidenced by the effective dose measurement. The effective dose efficiency (eDE) managed to incorporate the effective dose into the eDQE metric and has been evaluated in chest radiographs [12].

However, in our understanding the incorporation of the effective dose value into the eDQE metric could influence the choice of an optimal technique over another with better performance in radiography systems. Therefore, in this present study we chose to analyze the eDQE and the effective dose separately and balance those two parameters to choose radiographic techniques with lower risk for the patient. 
The aim of this paper was to investigate the image quality of the skull, chest, and pelvic examinations in computed radiography systems. We performed the VGA of an anthropomorphic phantom and analyzed physical parameters such as effective detective quantum efficiency, effective dose and contrast-to-noise ratio.

\section{Methodology}

The radiographic system and the phantoms description

An Agfa CR 85-X digitizer (Agfa-Gevaert Group, Mortsel, BE) was used with MD 4.0 general cassette plates $\left(35 \mathrm{~cm} \times 35 \mathrm{~cm}^{2}\right.$, effective pixel pitch of $0.1 \mathrm{~mm}$ ). The CR system and the cassette plates were tested in accordance with the quality control tests [13]. The general purpose X-ray room consisted of three-phase equipment (Multix B, Siemens AG Medical Engineering, Germany) with a total inherent filtration of $2.5 \mathrm{~mm}$ of aluminum and employing a stationary grid with a 5:1 grid ratio. Aiming for maximum reproducibility, one image plate (IP) was used for each examination and all procedures were repeated three times. In addition, a delay of 10 minutes occurred between exposures and readings.

The study was performed with two different phantoms: the homogeneous phantom and the anthropomorphic (Alderson Rando - AR). The homogeneous phantom was the patient equivalent phantom (PEP) for skull, pelvis and chest (American National Standard Institute PH2/43, 1982). The skull and pelvis were simulated by the same phantom configuration (PEP Skull/Pelvis) since, according to Gray [14], scattering in these anatomic regions is similar. The skull/pelvis PEP consisted of four pieces of clear acrylic polymethylmethacrylate (PMMA) measuring $30.5 \times 30.5 \times 2.54 \mathrm{~cm}^{3}$, a piece of aluminum (type 1100 alloy) measuring $30.5 \times 30.5 \times 0.3 \mathrm{~cm}^{3}$, and an additional piece of PMMA measuring $30.5 \times 30.5 \times 5.08 \mathrm{~cm}^{3}$. The chest PEP consisted of four pieces of PMMA measuring $30.5 \times 30.5 \times 2.54 \mathrm{~cm}^{3}$, a piece of aluminum measuring $30.5 \times 30.5 \times 0.3 \mathrm{~cm}^{3}$, and a $5.08 \mathrm{~cm}$ air gap. The anthropomorphic phantom was the Alderson-Rando (AR) phantom $[15,16]$, which consisted of a natural human skeleton embedded in a synthetic isocyanate rubber with a lung substitute and air cavities. This simulates an average male patient $(\sim 73 \mathrm{~kg})$. We also inserted tubular structures ( $4 \mathrm{~mm}$ in diameter and $15 \mathrm{~cm}$ in length) containing water into the chest region to simulate a vascular pattern.

Table 1

Skull test techniques obtained with the skull PEP with the kVp, mAs and VGA values.

\begin{tabular}{rlllll}
\hline $\mathrm{kVp}$ & $\mathrm{mAs}$ values/VGA scores & & & \\
\hline 70 & 7.1 & 8 & 9 & 10.0 & 11 \\
& -0.67 & 1.33 & 1.67 & 0.67 & -0.67 \\
75 & 5 & 5.6 & 6.3 & 7.1 & 8 \\
& 1.00 & 1.67 & 2.00 & 0.33 & 0.67 \\
81 & 3.6 & 4 & 4.5 & 5.0 & 5.6 \\
& 0.67 & 1.00 & 1.67 & 1.33 & 0.33 \\
85 & 2.8 & 3.2 & 3.6 & 4.0 & 4.5 \\
& 1.00 & 0.00 & 2.00 & 0.67 & -0.33 \\
90 & 2.2 & 2.5 & 2.8 & 3.2 & 3.6 \\
& 0.33 & 2.00 & 0.67 & 0.67 & -0.33 \\
96 & 1.8 & 2 & 2.2 & 2.5 & 2.8 \\
& 1.33 & 1.00 & 2.00 & -0.67 & -0.67 \\
102 & 1.4 & 1.6 & 1.8 & 2.0 & 2.2 \\
& 0.00 & 2.00 & 1.00 & 1.33 & 0.67 \\
105 & 1.25 & 1.4 & 1.6 & 1.8 & 2 \\
& 0.67 & 2.00 & 1.33 & 0.33 & 0.00 \\
109 & 1.25 & 1.4 & 1.6 & 1.8 & \\
& 2.00 & 0.67 & 0.67 & 0.67 & \\
117 & 1.25 & 1.4 & & & \\
& 2.00 & 0.67 & & & \\
\hline
\end{tabular}

Table 2

Pelvis test techniques obtained with the pelvic PEP with the kVp, mAs and VGA values.

\begin{tabular}{rlllll}
\hline $\mathrm{kVp}$ & $\mathrm{m}$ As values/VGA scores & & & \\
\hline 70 & 7.1 & 8 & 9 & 10.0 & \\
& 0.67 & 1.00 & 1.67 & 0.33 & \\
75 & 5 & 5.6 & 6.3 & 7.1 & 0.33 \\
& 0.67 & -0.67 & 1.67 & 0.67 & 5.6 \\
81 & 3.6 & 4 & 4.5 & 5.0 & -1.33 \\
& -1.33 & 0.67 & 2.00 & 1.00 & 0.3 \\
85 & 2.8 & 3.2 & 3.6 & 4.0 & \\
& 0.67 & 0.33 & 2.00 & 0.00 & \\
90 & 2.2 & 2.5 & 2.8 & 4.0 & \\
& 1.00 & 1.00 & 1.67 & 0.67 & \\
96 & 2 & 2.5 & 2.8 & & 0.00 \\
& -0.33 & 2.00 & 1.00 & & \\
102 & 1.4 & 1.6 & 1.8 & 2.0 & \\
& 0.00 & 0.67 & -0.67 & 2.00 & \\
105 & 1.25 & 1.4 & 1.8 & 2.0 & \\
& 1.00 & -0.33 & 1.33 & 0.00 & \\
109 & 1.25 & 1.4 & 1.6 & 1.8 & \\
& 0.33 & 0.00 & 2.00 & 0.33 & \\
\hline \multirow{2}{*}{117} & 1.25 & 1.4 & & & \\
& -0.67 & 1.67 & & & \\
\hline
\end{tabular}

Imaging and VGA image quality evaluations

An initial series of exposures were performed with the PEP phantom. Nominal peak tube potentials varied between 70 and $117 \mathrm{kVp}$ in approximately $5 \mathrm{kVp}$ steps. Each $\mathrm{kVp}$ correlated with $5 \mathrm{mAs}$ values. This procedure resulted in radiological techniques (hence forth called test-techniques) for the skull, chest, and pelvic examinations which are described in Tables 1-3. The lgM values (Agfa exposure index) were monitored in each test-technique by collimating the images to the entire area of the PEP. The AR phantom $[15,17]$ was then imaged at the appropriate anatomical regions using the test-techniques. All chest techniques were generated with exposure times less than $20 \mathrm{~ms}$ to avoid cardiac motion artifacts [2].

For all measurements, the PEP was centered in the radiation field. The source-detector distance (SDD) was $1.0 \mathrm{~m}$ to image the skull and pelvis, and $1.8 \mathrm{~m}$ for chest. The tube collimator was adjusted to yield a radiation field of $35.0 \times 35.0 \mathrm{~cm}^{2}$. Entrance Surface Doses (ESDs) were monitored on the surface of the PEP with a dosimetric system that consisted of a 9015 electrometer (Radcal Corp., Monrovia, CA, USA) and a properly calibrated ionization chamber (model 10X5-6 cc, Radcal Corp.). The effective dose (ED) values were estimated from ESDs measured, simulations and organ weighting factors obtained from ICRP 103 [18] using an online Monte Carlo

Table 3

Chest test techniques obtained with the chest PEP with the $\mathrm{kVp}, \mathrm{mAs}$ and VGA values.

\begin{tabular}{rcclllll}
\hline $\mathrm{kVp}$ & \multicolumn{7}{c}{$\mathrm{m}$ As values/VGA scores } \\
\hline 75 & 5.6 & 6.3 & 7.1 & 8.0 & 9 & 10 & - \\
& -0.67 & 0.33 & 1.67 & 1.00 & 1.00 & -1.00 & \\
81 & 4.5 & 5 & 5.6 & 6.3 & 7.1 & - & - \\
& 1.00 & 2.00 & -0.33 & 0.67 & -0.33 & & \\
85 & 3.6 & 4 & 4.5 & 5.0 & 5.6 & - & - \\
& 0.67 & 2.00 & 0.67 & 0.33 & -0.33 & & - \\
90 & 2.5 & 2.8 & 3.2 & 3.6 & 4 & - & - \\
& 0.67 & 0.67 & 1.67 & 1.00 & 0.33 & & \\
96 & 1.6 & 2.2 & 2.5 & 2.8 & 3.2 & 3.6 & \\
& -1.67 & -0.33 & 0.33 & 1.33 & 2.00 & 0.33 & \\
102 & 1.25 & 1.4 & 1.6 & 1.8 & 2 & 2.2 & 2.5 \\
& -1.00 & -1.33 & 0.00 & 1.00 & 1.33 & 1.67 & 0.00 \\
105 & 1.4 & 1.6 & 1.8 & 2.2 & 2.8 & - & - \\
& -1.67 & -0.67 & 0.67 & 1.00 & 1.67 & & - \\
109 & 1.25 & 1.4 & 1.6 & 1.8 & 2 & - & - \\
& -2.00 & -0.33 & 0.67 & 1.00 & 2.00 & & \\
117 & 1.25 & 1.4 & 1.6 & 1.8 & & & \\
& 0.33 & 1.33 & 2.00 & 1.33 & & & \\
\hline
\end{tabular}


Table 4

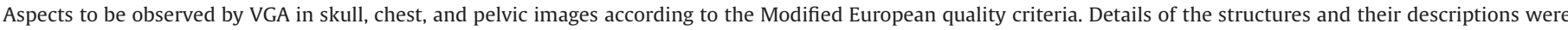
extracted from structures that can be seen in the AR phantom.

\begin{tabular}{|c|c|c|}
\hline Skull & Chest & Pelvis \\
\hline $\begin{array}{l}\text { Visually sharp reproduction of the } \\
\text { frontal sinus, maxillar sinus, ethmoid } \\
\text { cells and apex of the petrous temporal } \\
\text { bones and the internal auditory canals } \\
\text { - Visually sharp reproduction of the } \\
\text { outer and inner lamina of the } \\
\text { cranial vault }\end{array}$ & $\begin{array}{l}\text { - Visually sharp reproduction of the vascular pattern in } \\
\text { the whole lung, particularly the peripheral vessels } \\
\text { - Visually sharp reproduction of the upper half trachea } \\
\text { - Visually sharp reproduction of the borders of the heart } \\
\text { and aorta } \\
\text { - Visually sharp reproduction of the diaphragm and } \\
\text { lateral costo-phrenic angles } \\
\text { - Visualization of the mediastinum } \\
\text { - Visualization of the spine through the heart shadow }\end{array}$ & $\begin{array}{l}\text { - Visually sharp reproduction of the sacrum and its } \\
\text { intervertebral foramina } \\
\text { - Visually sharp reproduction of the pubic and ischial rami } \\
\text { - Visually sharp reproduction of the sacroiliac joints } \\
\text { - Visually sharp reproduction of the necks of the femora } \\
\text { - Visually sharp reproduction of the spongiosa and } \\
\text { corticalis and the trochanters bone texture } \\
\text { - Visualization of the pelvis wall soft tissues } \\
\text { - Visualization of the region of the vertebral discs }\end{array}$ \\
\hline
\end{tabular}

simulation software, CALDose_X 5.0, available at www.caldose.org and extensively used for this purpose [19-22].

In the anthropomorphic phantom, image quality was subjectively assessed by the VGA method according to quality criteria modified to the AR phantom as seen in Table 4 [2]. Three observers assessed image quality by assigning scores from -2 to 2 , including zero $[7,8]$. All observers were radiologists with more than 10 years of experience. A score of 2 corresponded to images which the observers could visualize all structures described in Table 4 . When some structure was not clearly visualized, the score was lowered. Observers were allowed to change window and level settings of each image to better visualize the structures. At least one test-technique in each $\mathrm{kVp}$ value received the score of +2 , as highlighted in Tables $1-3$. These techniques were found to be optimal techniques and passed through physical assessments of eDQE and CNR.
VGA analysis was performed under identical conditions (a room with dimmed light and surrounding illuminant on near 30 lux). The luminance of the monitor was measured at 5 previously defined points and the standard deviation for the different points was less than $5 \%[13]$.

\section{Physical parameters used to assess image quality}

\section{eDQE measurements}

The eDQE measurement was used to estimate the system performance in a clinically relevant context for all optimal techniques of each region (i.e., skull, chest, and pelvis). eDQE includes attributes such as magnification, focal spot blur, scattered radiation, and the presence of an antiscatter grid [23]. This is defined as:

Table 5

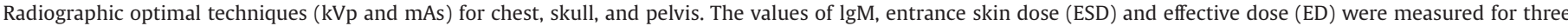

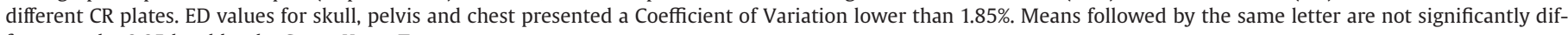
ferent at the 0.05 level by the Scott-Knott Test.

\begin{tabular}{|c|c|c|c|c|}
\hline Examination & Optimal technique & $\lg M$ & $\mathrm{ESD}(\mu \mathrm{Gy})$ & $\mathrm{ED}(\mu \mathrm{Sv})$ \\
\hline Skull Agfa CR 85-X & $70.0 \mathrm{kVp} ; 9.0 \mathrm{mAs}$ & $1.94 \pm 0.01$ & 775.1 & $13.69 \pm 0.21 a$ \\
\hline \multirow[t]{11}{*}{$\mathrm{SDD}=100 \mathrm{~cm}$} & $75.0 \mathrm{kVp} ; 6.3 \mathrm{mAs}$ & $1.96 \pm 0.01$ & 634.3 & $12.53 \pm 0.19 b$ \\
\hline & $81.0 \mathrm{kVp} ; 4.5 \mathrm{mAs}$ & $1.96 \pm 0.01$ & 531.4 & $11.75 \pm 0.17 c$ \\
\hline & $85.0 \mathrm{kVp} ; 3.6 \mathrm{mAs}$ & $1.97 \pm 0.01$ & 478.7 & $11.31 \pm 0.17 d$ \\
\hline & $90.0 \mathrm{kVp} ; 2.8 \mathrm{mAs}$ & $1.96 \pm 0.01$ & 414.4 & $10.54 \pm 0.18 \mathrm{e}$ \\
\hline & $96.0 \mathrm{kVp} ; 2.2 \mathrm{mAs}$ & $1.97 \pm 0.01$ & 378.0 & $10.37 \pm 0.15 \mathrm{e}$ \\
\hline & $102.0 \mathrm{kVp} ; 1.6 \mathrm{mAs}$ & $1.95 \pm 0.01$ & 321.2 & $9.45 \pm 0.13 f$ \\
\hline & $105.0 \mathrm{kVp} ; 1.4 \mathrm{mAs}$ & $1.96 \pm 0.01$ & 309.5 & $9.42 \pm 0.14 f$ \\
\hline & $109.0 \mathrm{kVp} ; 1.25 \mathrm{mAs}$ & $1.94 \pm 0.01$ & 298.3 & $9.41 \pm 0.14 \mathrm{f}$ \\
\hline & $117.0 \mathrm{kVp} ; 1.25 \mathrm{mAs}$ & $2.00 \pm 0.01$ & 331.1 & $11.19 \pm 0.16 d$ \\
\hline & Routine skull & & & \\
\hline & $70.0 \mathrm{kVp} ; 11.0 \mathrm{mAs}$ & $2.01 \pm 0.02$ & 967.3 & $16.59 \pm 0.17$ \\
\hline Pelvis Agfa CR 85-X & $70.0 \mathrm{kVp} ; 9.0 \mathrm{mAs}$ & $1.94 \pm 0.01$ & 832.4 & $142.4 \pm 2.3 a$ \\
\hline \multirow[t]{11}{*}{$\mathrm{SDD}=100 \mathrm{~cm}$} & $75.0 \mathrm{kVp} ; 6.3 \mathrm{mAs}$ & $1.96 \pm 0.01$ & 675.2 & $123.6 \pm 1.9 \mathrm{~d}$ \\
\hline & $81.0 \mathrm{kVp} ; 4.5 \mathrm{mAs}$ & $1.96 \pm 0.01$ & 543.0 & $109.5 \pm 1.6 \mathrm{e}$ \\
\hline & $85.0 \mathrm{kVp} ; 3.6 \mathrm{mAs}$ & $1.97 \pm 0.01$ & 521.8 & $111.6 \pm 1.6 \mathrm{e}$ \\
\hline & $90.0 \mathrm{kVp} ; 2.8 \mathrm{mAs}$ & $1.97 \pm 0.01$ & 555.9 & $125.7 \pm 2.2 \mathrm{~d}$ \\
\hline & $96.0 \mathrm{kVp} ; 2.5 \mathrm{mAs}$ & $1.94 \pm 0.02$ & 544.3 & $133.7 \pm 1.9 c$ \\
\hline & $102.0 \mathrm{kVp} ; 2 \mathrm{mAs}$ & $1.95 \pm 0.01$ & 510.8 & $134.4 \pm 1.9 c$ \\
\hline & $105.0 \mathrm{kVp} ; 1.8 \mathrm{mAs}$ & $1.96 \pm 0.01$ & 503.0 & $137.1 \pm 1.6 b$ \\
\hline & $109.0 \mathrm{kVp} ; 1.6 \mathrm{mAs}$ & $2.01 \pm 0.02$ & 484.2 & $136.9 \pm 1.5 b$ \\
\hline & $117.0 \mathrm{kVp} ; 1.4 \mathrm{mAs}$ & $2.02 \pm 0.02$ & 474.2 & $144.3 \pm 1.7 \mathrm{a}$ \\
\hline & Routine pelvis & & & \\
\hline & $75.0 \mathrm{kVp} ; 9.0 \mathrm{mAs}$ & $2.03 \pm 0.02$ & 971.5 & $166.5 \pm 1.7$ \\
\hline$=$ Chest Agfa CR 85-X & $75.0 \mathrm{kVp} ; 7.1 \mathrm{mAs}$ & $1.95 \pm 0.01$ & 174.8 & $30.7 \pm 0.86 a$ \\
\hline \multirow[t]{10}{*}{$\mathrm{SDD}=180 \mathrm{~cm}$} & $81.0 \mathrm{kVp} ; 5.0 \mathrm{mAs}$ & $1.94 \pm 0.01$ & 144.0 & $27.8 \pm 0.81 b$ \\
\hline & $85.0 \mathrm{kVp} ; 4.0 \mathrm{mAs}$ & $1.94 \pm 0.01$ & 128.1 & $26.0 \pm 0.72 c$ \\
\hline & $90.0 \mathrm{kVp} ; 3.2 \mathrm{mAs}$ & $1.92 \pm 0.01$ & 109.0 & $23.5 \pm 0.76 e$ \\
\hline & $96.0 \mathrm{kVp} ; 3.2 \mathrm{mAs}$ & $2.00 \pm 0.01$ & 101.0 & $23.2 \pm 0.71 \mathrm{e}$ \\
\hline & $102.0 \mathrm{kVp} ; 2.2 \mathrm{mAs}$ & $1.95 \pm 0.01$ & 102.8 & $25.0 \pm 0.85 d$ \\
\hline & $105.0 \mathrm{kVp} ; 2.2 \mathrm{mAs}$ & $2.00 \pm 0.01$ & 109.4 & $27.3 \pm 0.82 b$ \\
\hline & $109.0 \mathrm{kVp} ; 2.0 \mathrm{mAs}$ & $2.00 \pm 0.01$ & 107.7 & $27.7 \pm 0.85 b$ \\
\hline & $117.0 \mathrm{kVp} ; 1.6 \mathrm{mAs}$ & $2.00 \pm 0.01$ & 100.0 & $27.2 \pm 0.82 b$ \\
\hline & Routine chest & & & \\
\hline & $85.0 \mathrm{kVp} ; 11.0 \mathrm{mAs}$ & $2.32 \pm 0.03$ & 249.6 & $53.4 \pm 0.55$ \\
\hline
\end{tabular}


$\operatorname{eDQE}\left(\mathrm{f}^{\prime}\right)=\frac{\operatorname{MTF}\left(\mathrm{f}^{\prime}\right) \dagger \times(1-\mathrm{SF}) \dagger}{\operatorname{NNPS}\left(f^{\prime}\right) \times T F \times E \times q}$

where $\operatorname{eDQE}\left(\mathrm{f}^{\prime}\right)$ is the effective $\mathrm{DQE}$ at the magnified frequency of $\mathrm{f}^{\prime}, \operatorname{MTF}\left(\mathrm{f}^{\prime}\right)$ is the measured MTF, SF is the measured scatter fraction, $\mathrm{NNPS}\left(\mathrm{f}^{\prime}\right)$ is the normalized noise power spectrum, TF is the measured transmission fraction through the phantom, $\mathrm{E}$ is the measured exposure at the detector plane, and q is the total number of incident quanta per unit area. The term q can be estimated from a measurement of the actual exposure at the detector input or estimated with sufficient accuracy if the HVL is measured for a particular test condition [24]. Thus, the HVL using the PEP phantom was measured to determine the q value for each test technique. To compare the results of eDQE between the test techniques, $\mathrm{EDQE}$ values were averaged in the spatial frequencies between 0.5 and $2.0 \mathrm{~mm}^{-1}$.

Image data were all obtained 'for processing' prior to the application of image processing in the $\mathrm{CR}$ system. All image pixel values were linearized according to Eq. (2) to lend a generalized relation with exposure in the detector plane [25], based on the measured CR-85X response function.

$0.61 K^{1.3}-0.13=P \rightarrow \mathrm{P}^{\prime}=\left(\frac{P+0.13}{0.61}\right)^{0.77}$

where $\mathrm{P}$ is the pixel value, $\mathrm{K}$ is the air exposure (kerma), and $\mathrm{P}^{\prime}$ is the new pixel value.

As the first component of eDQE (from Eq. (1)) assessment, the MTF was measured with an angle edge technique. The edge test device consisted of a $1.5 \mathrm{~mm}$ Cu plate $\left(10.0 \times 10.0 \mathrm{~cm}^{2}\right)$ placed in front and at the center of the phantoms. Image data was processed to obtain the presampled MTF in a direction perpendicular to the edge. In summary, the processing of the acquired edge image involved the following: the angle of the edge transition in the image was determined, then the $2 \mathrm{D}$ data of the edge were projected along the determined angle into a one-dimensional estimate of the edge spread function (ESF). The ESF data were smoothed and
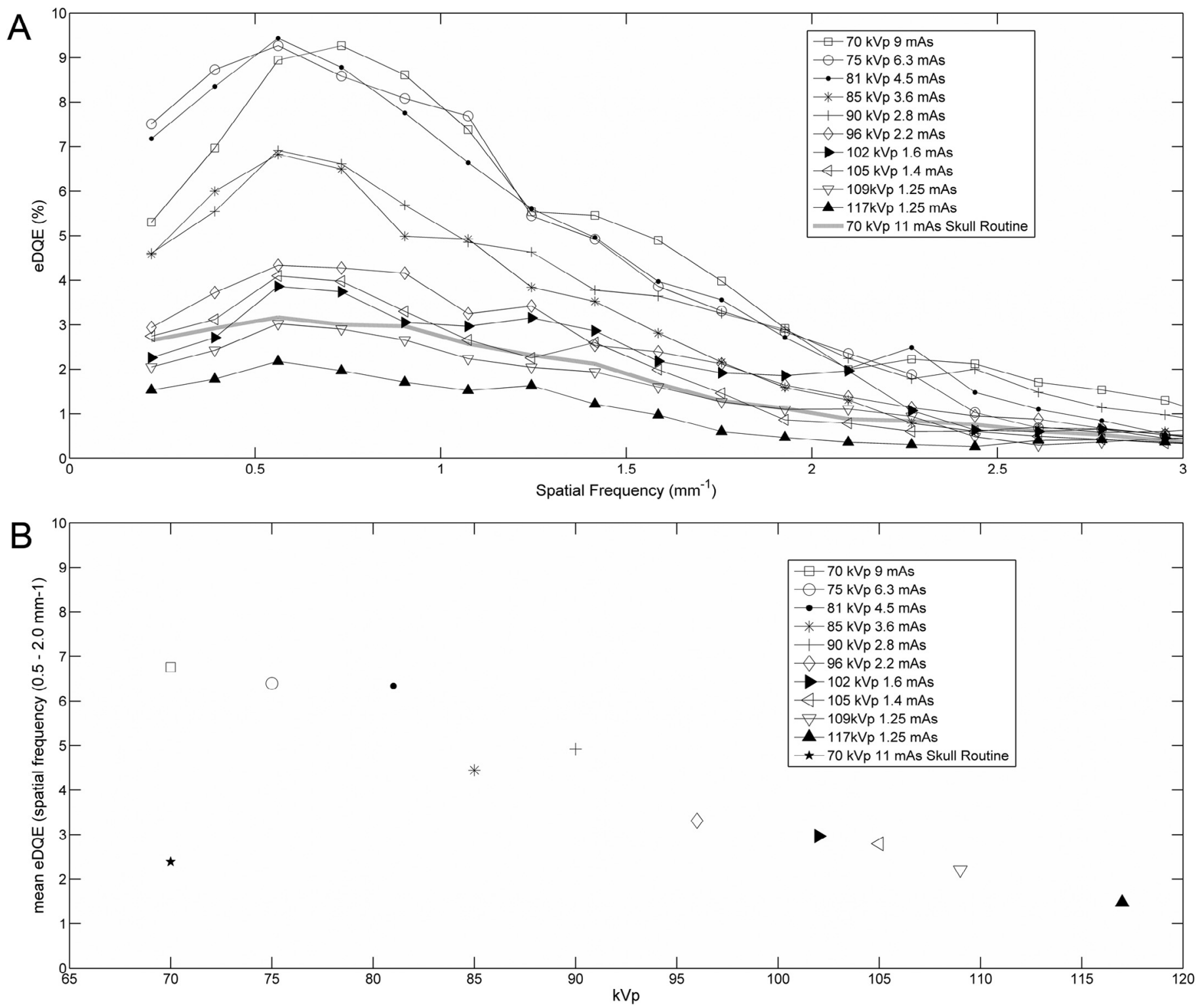

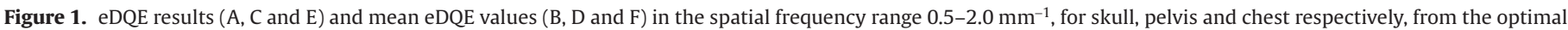

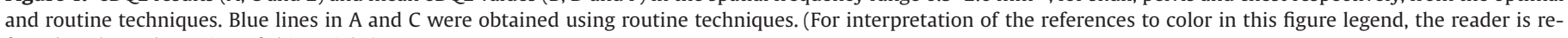
ferred to the web version of this article.) 
differentiated to obtain the line spread function (LSF). To obtain the MTF, a fast Fourier transform (FFT) was applied to the oversampled LSF [26]. All MTF images were analyzed through an algorithm developed in Matlab®.

The Noise Power Spectrum (NPS) was measured on the homogeneous images using the PEP placed in front of the detector surface. NPS was measured using an established international standard [26]. The normalized noise power spectrum (NNPS) is expressed in $\mathrm{mm}^{2}$ and is computed by Eq. (3).

$\operatorname{NNPS}(u, v)=\frac{\operatorname{NPS}(u, v)}{(\text { large area signal })^{2}}$

Determination of the eDQE requires knowing other associated quantities: the bean transmission fraction (TF), the scatter fraction (SF) and the ideal squared signal-to-noise ratio per unit exposure [23]. All of those values were measured using clinical geometry on the PEP phantom.

The beam TF was measured as the ratio of the average exposure with the phantom present to that without. The phantoms were positioned more than $30 \mathrm{~cm}$ from the detector to avoid backscatter. Exposure measurements were made with a calibrated ionization chamber positioned in the beam path $5 \mathrm{~cm}$ before the phantom and $5 \mathrm{~cm}$ after the phantom. The SF was measured with a beam stop device adjacent to the surface of the phantom and facing the X-ray source. The beam stop device was composed of 8 lead cylinders (6 $\mathrm{mm}$ length and $3 \mathrm{~mm}$ diameter) positioned in the center of the phantoms. SF was calculated as the ratio of attenuated signal to background that was averaged across all beam stop devices.

\section{Contrast-to-noise ratio}

The CNR was measured using a thin piece of polyvinyl chloride (PVC) inserted on a uniform acrylic plate $\left(2.0 \times 15.0 \times 15.0 \mathrm{~cm}^{3}\right)$ and coupled to the PEP phantom in the same assembly previously used. CNR for each image was computed using Eq. (4).

$\mathrm{CNR}=\frac{\mathrm{X}_{1}-\mathrm{X}_{2}}{\sqrt{\frac{\sigma_{1}^{2}+\sigma_{2}^{2}}{2}}}$
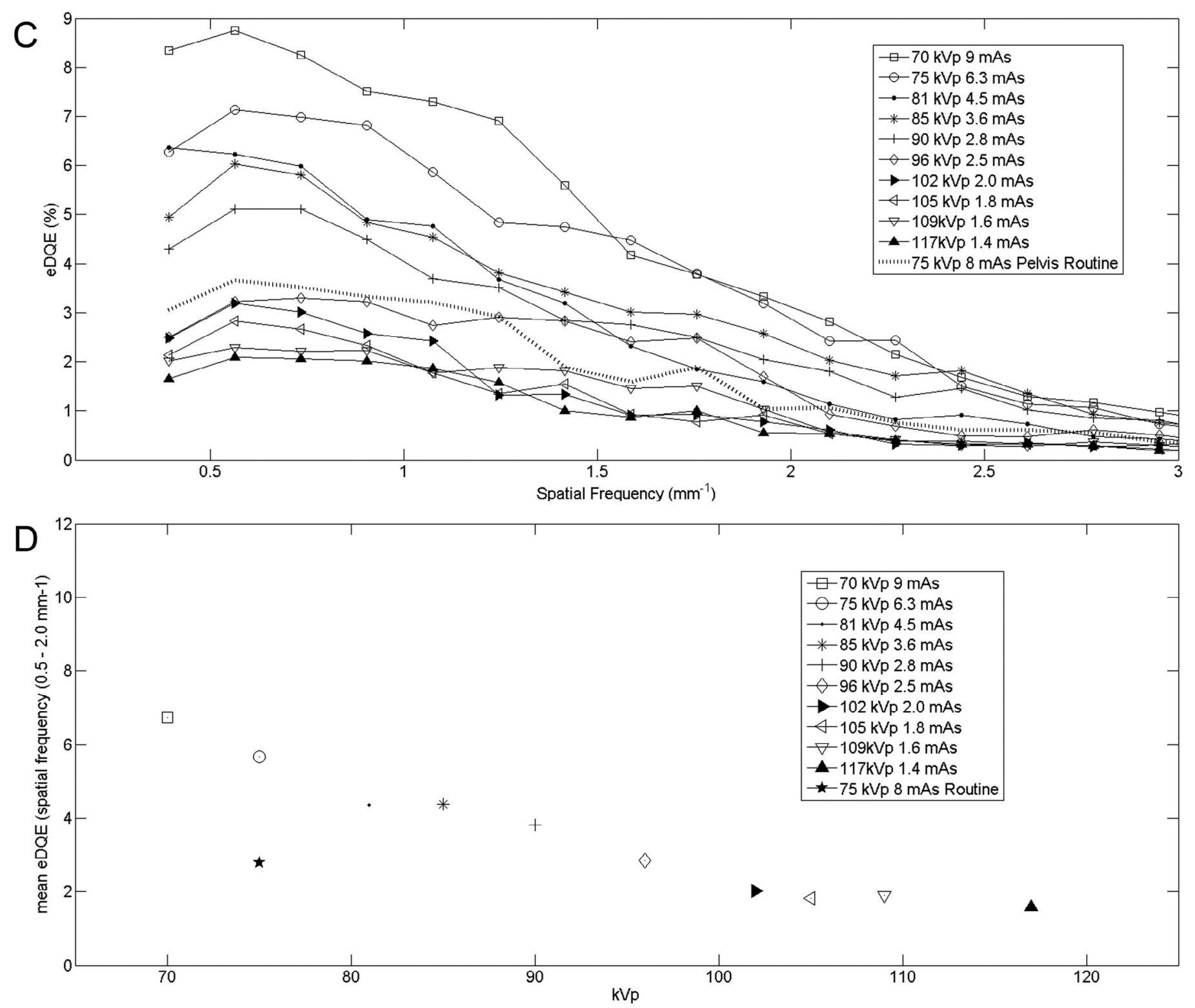

Fig. 1. (continued) 
Where $X_{1}$ is the average value of the pixels in a region of interest (ROI) within PVC region, $\mathrm{X}_{2}$ is the average value of the pixels in ROI within the background of the phantom, $\sigma_{1}$ and $\sigma_{2}$ are the standard deviations of $\mathrm{X}_{1}$ and $\mathrm{X}_{2}$, respectively.

\section{The choice of gold standard techniques}

A gold standard (GS) radiographic technique was chosen from the set of optimal techniques according to the following criteria:

(i) Techniques that had minimal value for effective doses.

(ii) If more than one optimal technique satisfied (i) the one with the highest values for physical parameters, such as eDQE or CNR were chosen.

ED values of optimal techniques of each anatomical region were analyzed by ANOVA and means were compared by the ScottKnott test to determine whether they were statistically different or not. We also compared the GS technique with routine techniques used in our institution. Those routine techniques were derived from interview with different radiology technicians from the diagnostic imaging sector of our institution.

\section{Results}

Table 5 shows the optimal and routine radiographic techniques for skull, chest and pelvis with their $\operatorname{lgM}$ values, Entrance Skin Dose (ESD) and Effective Dose (ED). All optimal techniques listed had VGA scores of +2 . The average exposure index $(\operatorname{lgM})$ of optimal images was $1.96 \pm 0.03$.

Figure 1 compares the eDQE of the optimal and routine protocols for skull, pelvis and chest (A, C and E), and its corresponding mean eDQE values in the spatial frequency range of $0.5-2.0 \mathrm{~mm}^{-1}$ (B, D and F).

Figure 2 shows the CNR as a function of $\mathrm{kVp}$ for techniques used to image the PEP phantom coupled to the PVC insert in acrylic. Between the minimum and maximum $\mathrm{kVp}$ values, CNR values were reduced by $43.7 \%$ for the skull, $35.9 \%$ for the chest, and $23.6 \%$ for the pelvis.
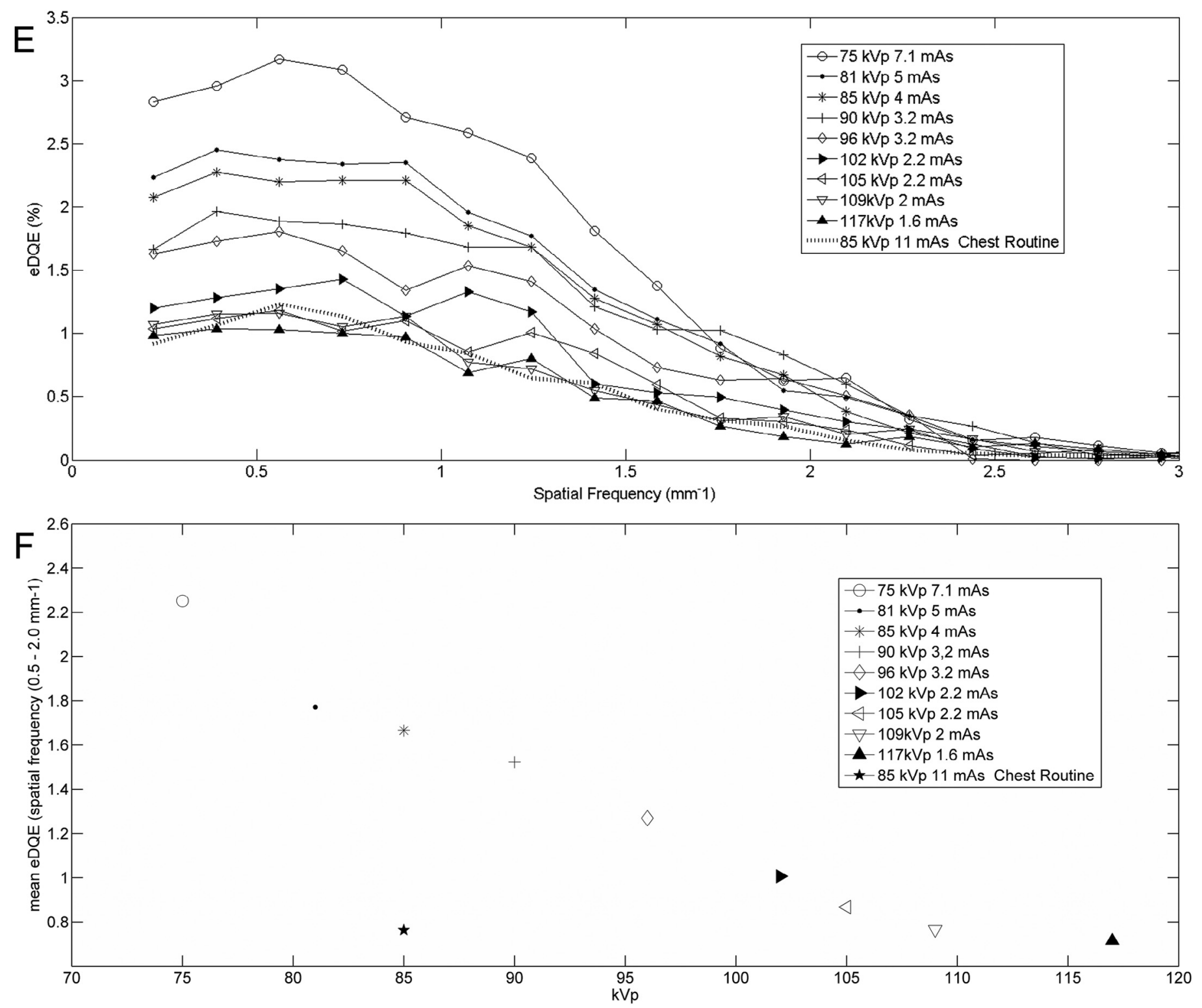

Fig. 1. (continued) 

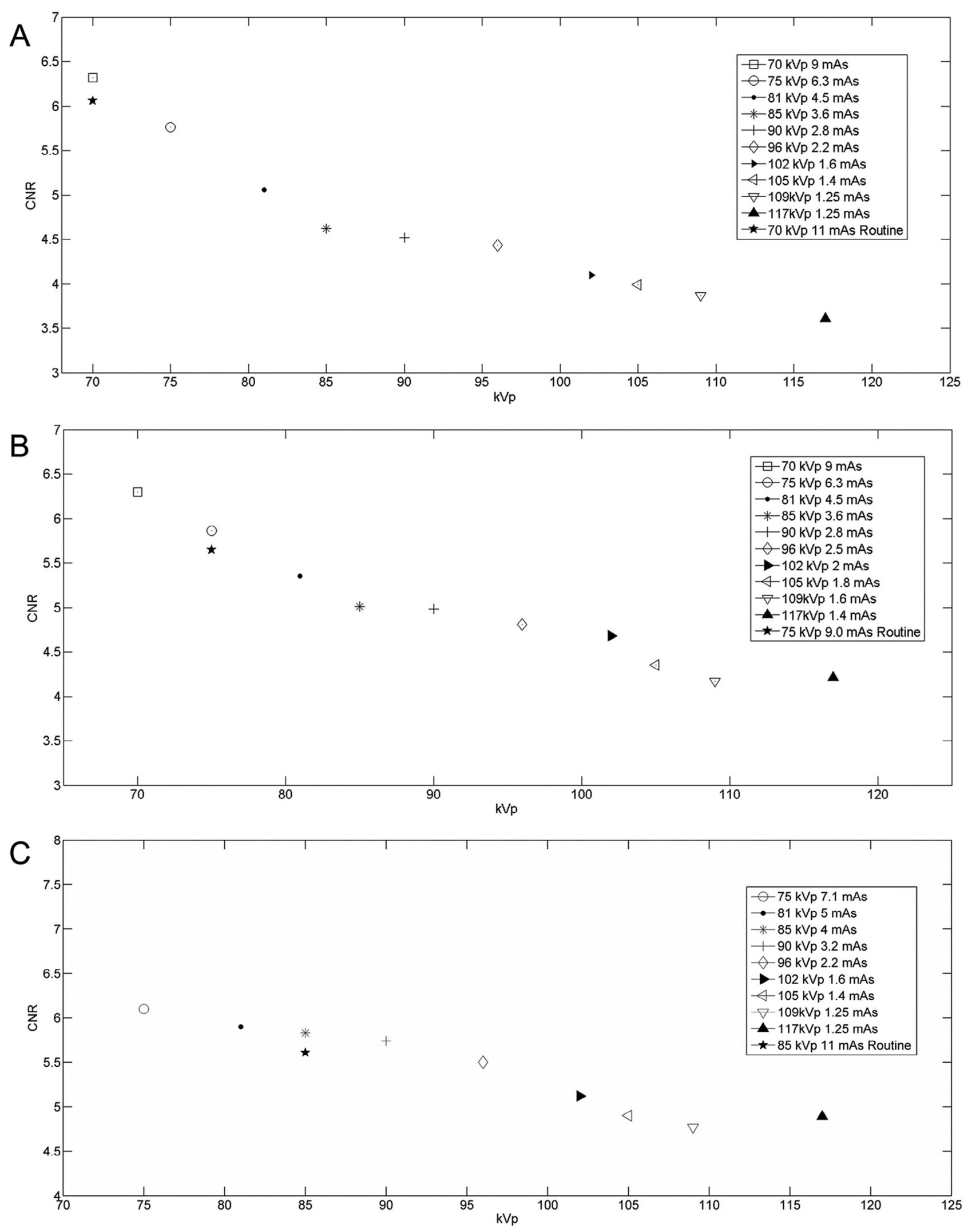

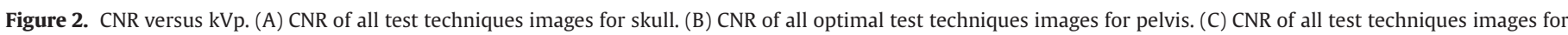
chest. 


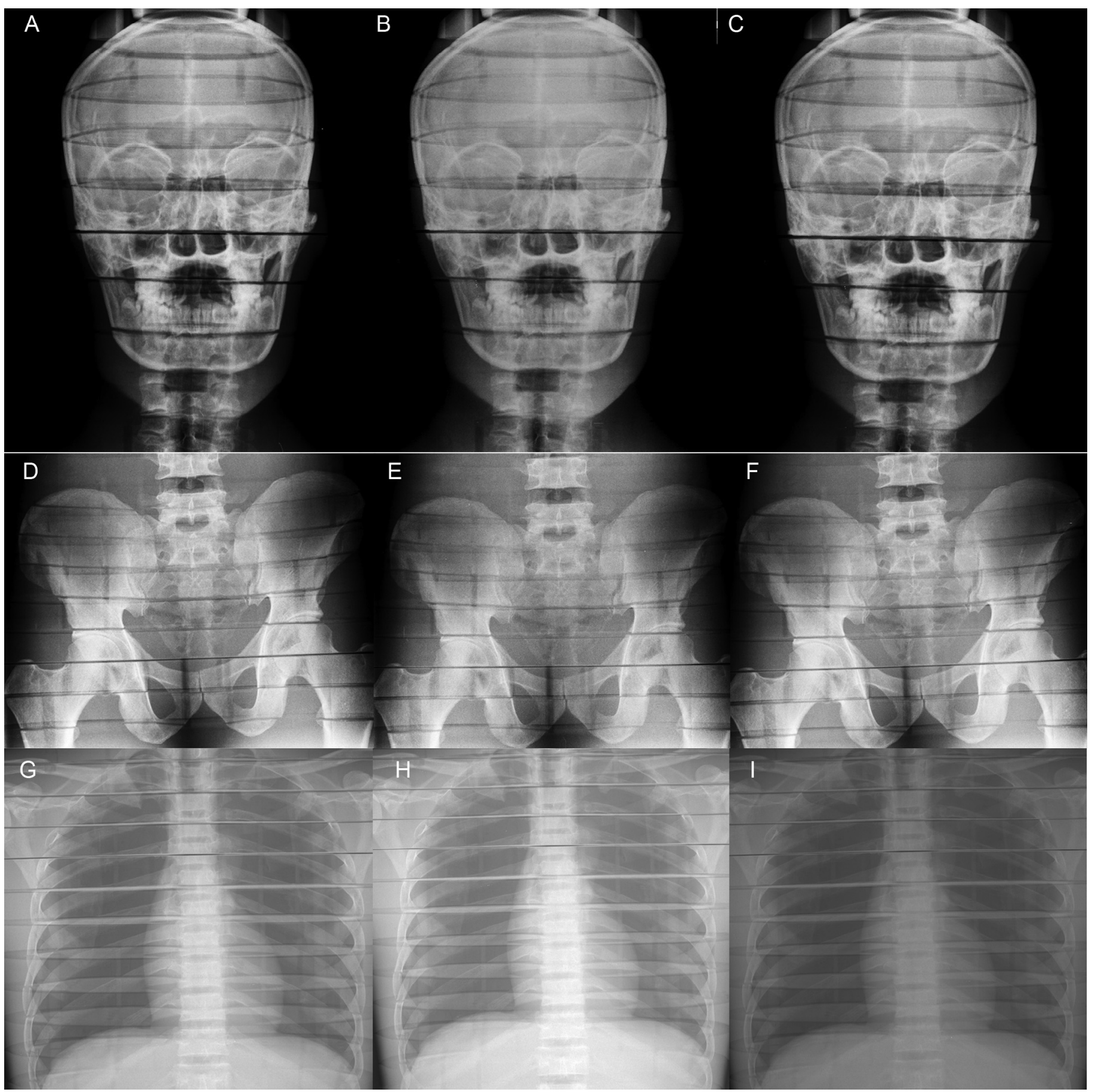

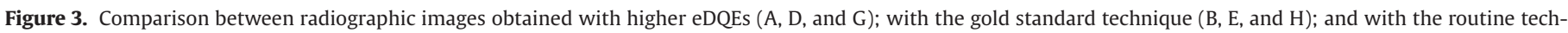
niques of our institution are shown in (C, F, and I). All images were evaluated with scores of +2 by radiologists for skull, pelvis and chest.

The GS techniques to be used in our routine have been chosen as follows $102 \mathrm{kVp} / 1.6 \mathrm{mAs}$ for skull; $81 \mathrm{kVp} / 4.5 \mathrm{mAs}$ for pelvis and $90 \mathrm{kVp} / 3.2 \mathrm{mAs}$ for chest. Those GS techniques were those who met the criteria set out in methodology.

Figure 3 shows images obtained using techniques with the higher eDQE values (A, D, G) compared to those GS techniques $(B, E, H)$ and also with the routine techniques (C, F, I). Images obtained from higher eDQE techniques (lower $\mathrm{kVp}$ ) and GS techniques were not significantly different regarding their quality upon VGA evaluation since all techniques received the score +2 , including routine techniques.

\section{Discussion}

While our methodology is accurate it has certain limitations, which include no incorporation of the influence of image postprocessing in determinations of physical quantities MTF, NNPS and CNR and it has not been tested in other manufacture CR systems.

The eDQE performance of the Agfa CR 85-X system is similar to those found elsewhere [9]. There was a large difference in magnitude of the eDQE curves between different optimal techniques. The lowest tube voltages provided the best performance in terms of the $\mathrm{eDQE}$, in some cases the highest eDQE curve is $100 \%$ larger in 
comparison to the lowest eDQE. This should be explained with the Scatter fraction (SF) been increased with $\mathrm{kVp}$ and the factor (1$\mathrm{SF})^{2}$ contributed to decreased $\mathrm{eDQE}$ at higher $\mathrm{kVp}$. Scatter faction (SFs) ranged from 0.38 to 0.48 in the chest and from 0.25 to 0.36 in skull and pelvis. These values are in general agreement with the literature [16,27].

As expected CNR values decreased as $\mathrm{kVp}$ increased. The average value of eDQE through $0.5-2.0 \mathrm{pl} / \mathrm{mm}$ (Fig. 1) and CNR values (Fig. 2) were monotonically decreasing functions of the tube voltage values of the optimal techniques. Both eDQe and CNR combined with VGA scores and ED values helped clarify the choice of the gold standard techniques as final request (item-ii of methodology). Although physical quantities (eDQe and CNR) decreased with higher tube voltage values, ED values also decreased and image quality according to VGA analyses were maintained.

The comparison of effective doses for all optimal techniques is an essential part of the optimization of radiographic techniques. For all three anatomical regions the total effective dose (ED) reported in Table 5 is highest for routine techniques. For skull GS techniques, ED varied from 9.41 to $13.69 \mu \mathrm{Sv}$ and the lowest ED values were found between 102 and $109 \mathrm{kVp}$. For pelvic GS techniques ED varied from 109.5 to $144.3 \mu \mathrm{Sv}$ and the lowest ED values were found with the 81 and $85 \mathrm{kVp}$ techniques. For chest GS techniques ED varied from 23.2 to $30.7 \mu \mathrm{Sv}$ and the lowest ED values were found with 90 and $96 \mathrm{kVp}$. All those optimal techniques considered lowest did not differ statistically with the Scott-Knott test when compared with each other in each anatomical region.

We evaluated a set of test techniques for the skull, pelvis, and chest to determine Gold Standard techniques in computed radiography systems. The choice of the gold standard techniques was based on two well-defined criteria: effective dose values and physical parameters such as $\mathrm{eDQE}$ and CNR.

Gold standard techniques were of the same quality as the other optimal techniques according to VGA analysis. They were generated with substantial reductions of effective doses when compared to routine techniques and also presented an intermediate value of average eDQE.

Some authors demonstrated that lowering tube potentials increased the VGA analysis score and this should be accompanied by an increase in current ( $\mathrm{mA}$ ) to compensate for reduced intensity [16]. Our results show that with an appropriate range of exposure at detector plates, we could use higher tube potentials with lower current in the Agfa CR systems. This is an important protocol to reduce the ED in the radiographic acquisition and to extend the life of the X-ray tube. Our results support that the assessment of improved physical parameters of image quality such as eDQE and CNR, are not adequate alone for the choice of a gold standard technique and they should be followed by the subjective analysis, here presented by the VGA analysis. Results by Samei et al. [12] also underlined that eDQE would have limited use for technique optimization if used alone. Unlike other papers, we evaluated the three main anatomical structures held in our routine, skull, pelvis and chest, to show that our method is accurate and reproducible in different phantoms and geometric arrangements. Therefore, the GS techniques can be easily adapted for different thicknesses of phantoms following the procedure developed by Pina et al. [28].

\section{Conclusion}

This study highlights that optimization of radiological techniques must evaluate qualitative (such as VGA) and quantitative factors (such as eDQE, CNR and effective dose) to simultaneously obtain acceptable image quality and minimize X-ray doses to the patients. There is a range of acceptable techniques that produce adequate images for diagnosis (optimal images) in CR systems. This aspect allows the optimization process to be more focused on the patient dose without compromising diagnostic capabilities. The visual analysis and physical parameters should be considered simultaneously as a criterion for image optimization.

\section{Acknowledgments}

The authors wish to thank all clinical and technical personnel of the Botucatu Medical School Radiodiagnostic facility. Financial support was provided by the National Council for Scientific and Technological Development (CNPq) and Coordenação de Aperfeiçoamento de Pessoal de Nivel Superior (CAPES). The authors express their gratitude to C. Quini for his aid in figure design.

\section{References}

[1] ICRP. The 2007 recommendations of the international commission on radiological protection. ICRP publication 103. Ann ICRP 2007;37:1-332.

[2] Commission of the European Communities C. European guidelines on quality criteria for diagnostic radiographic images 16260. Luxembourg: European Communities; 1996.

[3] Stewart BK, Kanal KM, Perdue JR, Mann FA. Computed radiography dose data mining and surveillance as an ongoing quality assurance improvement process. AJR Am J Roentgenol 2007;189:7-11.

[4] Alzimami K, Sassi S, Alkhorayef M, Britten AJ, Spyrou NM. Optimisation of computed radiography systems for chest imaging. Nucl Instrum Methods Phys Res A 2009;600:513-18.

[5] International Commission on Radiological Protection. Conversion coefficients for use in radiological protection against external radiation. Oxford; New York: Published for the Commission by Pergamon Press; 1996.

[6] Chu RYL, Fisher J, Archer BR, Conway BJ, Goodsitt MM, Glaze S, et al. Physics AAoPiMbtAIo, editor. Standardized methods for measuring diagnostic X-ray exposures. New York: American Institute of Physics, 1990. AAPM Report No. 31

[7] Tingberg A, Sjostrom D. Optimisation of image plate radiography with respect to tube voltage. Radiat Prot Dosimetry 2005;114:286-93.

[8] Sandborg M, Tingberg A, Ullman G, Dance DR, Alm Carlsson G. Comparison of clinical and physical measures of image quality in chest and pelvis computed radiography at different tube voltages. Med Phys 2006;33:4169-75.

[9] Sund P, Bath M, Kheddache S, Mansson LG. Comparison of visual grading analysis and determination of detective quantum efficiency for evaluating system performance in digital chest radiography. Eur Radiol 2004;14:48-58.

[10] Kyprianou IS, Rudin S, Bednarek DR, Hoffmann KR. Generalizing the MTF and DQE to include $x$-ray scatter and focal spot unsharpness: application to a new microangiographic system. Med Phys 2005;32:613-26.

[11] Ranger NT, Samei E, Dobbins JT 3rd, Ravin CE. Assessment of detective quantum efficiency: intercomparison of a recently introduced international standard with prior methods. Radiology 2007;243:785-95.

[12] Samei E, Ranger NT, Dobbins JT, Ravin CE. Effective dose efficiency: an application-specific metric of quality and dose for digital radiography. Phys Med Biol 2011;56:5099-118

[13] (AAPM) AAoPiM. Acceptance testing and quality control of photostimulable storage phosphor imaging systems. AAPM report NO 93. College Park, MD; 2006.

[14] Gray JE. Quality control in diagnostic imaging : a quality control cookbook. Baltimore, MD: University Park Press; 1983.

[15] Shrimpton PC, Wall BF, Fisher ES. The tissue-equivalence of the Alderson Rando anthropomorphic phantom for X-rays of diagnostic qualities. Phys Med Biol 1981;26:133-9.

[16] Moore CS, Avery G, Balcam S, Needler L, Swift A, Beavis AW, et al. Use of a digitally reconstructed radiograph-based computer simulation for the optimisation of chest radiographic techniques for computed radiography imaging systems. Br J Radiol 2012;85:e630-9.

[17] White DR. Tissue substitutes in experimental radiation physics. Med Phys 1978;5:467-79.

[18] International Commission on Radiological Protection. The 2007 recommendations of the International Commission on Radiological Protection. Oxford, England: Published for the International Commission on Radiological Protection by Elsevier; 2007.

[19] Kramer R, Khoury HJ, Vieira JW. CALDose_X - a software tool for the assessment of organ and tissue absorbed doses, effective dose and cancer risks in diagnostic radiology. Phys Med Biol 2008;53:6437-59.

[20] Kramer R, Khoury HJ, Lopes C, Vieira JW. Equivalent dose to organs and tissues in hysterosalpingography calculated with the FAX (Female Adult voXel) phantom. Br J Radiol 2006;79:893-9.

[21] Kramer R, Khoury HJ, Vieira JW, Lima VJ. MAX06 and FAX06: update of two adult human phantoms for radiation protection dosimetry. Phys Med Biol 2006;51:3331-46.

[22] Kramer R, Santos AM, Brayner CA, Khoury HJ, Vieira JW, Lima FR. Application of the MAX/EGS4 exposure model to the dosimetry of the Yanango radiation accident. Phys Med Biol 2005;50:3681-95.

[23] Samei E, Ranger NT, MacKenzie A, Honey ID, Dobbins JT 3rd, Ravin CE. Effective DQE (eDQE) and speed of digital radiographic systems: an experimental methodology. Med Phys 2009;36:3806-17. 
[24] Beutel J. Handbook of medical imaging. Bellingham, WA: SPIE Press; 2000.

[25] Mackenzie A. Validation of correction methods for the non-linear response of digital radiography systems. Br J Radiol 2008;81:341-5.

[26] (IEC) IEC. Medical electrical equipment - characteristics of digital X-ray imaging devices - part 1: determination of the detective quantum efficiency IEC 62220-1. Geneva, Switzerland: IEC; 2003.
[27] Floyd CE Jr, Lo JY, Chotas HG, Ravin CE. Quantitative scatter measurement in digital radiography using a photostimulable phosphor imaging system. Med Phys 1991;18:408-13.

[28] Pina DR, Duarte SB, Morceli J, Ghilardi Netto T. Development of phantom for radiographic image optimization of standard patient in the lateral view of chest and skull examination. Appl Radiat Isot 2006;64:1623-30. 